CASE OF

CHLORAL POISONING TREATED BY TIIE ADMINISTRATION OF BELLADONNA.

BY J. MACKENZIE BOOTH, M. A., M.B., LECTULER ON DISEASES OF TILE EAR IN AIBERDEEN UNIVERSITY, AND
PHYSICIAN TO THE ABERDEEN GENERAL DISPENSARY.

IN the treatment of a case with which I had recently to deal, the antagonism of chloral hydrate and belladonna was strikingly manifested. The case was that of an active tradesman of about forty years of age, who for the last ten years has three or four times a year been given to heavy bouts of drunkenness, lasting from a few days to a few weeks, and terminating on most occasions only with the means of obtaining the alcoholic stimulant. At first he only had these bouts after being induced to have a drink with some of his comrades, but latterly when the craving comes on, as it always does after a few months' abstinence, he begins by consuming the methylated spirit (sometimes fully a pint) which enters into the composition of the varnish employed in his work, and after that is exhausted he drinks whatever alcohol he can obtain. For more than three years I have attended him at these times, and on one occasion at the end of a week of hard drinking, he got out of bed while unobserved and drank threequarters of a mixture containing 140 grains of chlora hydrate. Beyond an unusually long and deep sleep, lasting nearly twenty hours, he experienced no ill effects from the drug. About two months ago he again began by having recourse to his methylated spirit, and one afternoon, after a week's drinking, I was called in, and found him with the usual delirium potatorum. I was told that he had had a sleeping draught, obtained at a druggist's, but that it had had no effect in calming him, and that he was breaking everything in the house. A mixture containing two drachms of chloral hydrate and one of bromide of potassium was ordered, a fourth part of which was to be given at once, and repeated if necessary in half an hour. A few hours after, about midnight, $I$ was again sent for, and found that the patient had obtained the bottle containing the chloral, and had drunk its contents at a draught. He soon fell asleep, and shortly afterwards the pallor and lividity of his face and the faintness of his breathing alarmed the family, so that they again sent for assistance. He was now lying on his back, very still, the face very pallid and slightly blue, the respiration scarcely perceptible save by the slight puffing of his cheeks during expiration, and the pulse very weak, quick, and irregular (120 to 140). Talking to him in a loud voice, touching the conjunctiva, pinching the skin, shaking him, \&c. elicited no response. The pupils were in a state of semi-contraction. The profound depression of the respiratory and circulatory centres showed the patient to be in a dan. gerous condition. Strychnia first suggested itself as the most effective means of restoring the activity of these centres but tincture of belladonna being at hand, and remembering the effect of belladonna in keeping up the respiration unde large doses of morphia, I determined to try it. The patient was accordingly made to swallow nearly a teaspoonful of the tincture in a little water. In a few minutes the respiration became more perceptible, the heart's action more distinct, and the pulse-rate slower and stronger; and in a short time he could be roused by even slight excitation. I then left him, after putting the belladonna out of his reach, and telling his friends to give him twenty drops of it if he showed any sign of relapsing into his former condition. One such dose was given three hours later, when he seemed to be breathing less perceptibly than usual, and the friends said that he flushed up and muttered a good deal after it. Two days' rest in bed and a stomachic tonic set the patient on his legs again.

Belladonna, from its powerful action on the centres of circulation and respiration, has been successfully used in cases of poisoning by aconite and Calabar bean, and by its means the circulation and respiration can be kept up during the exhibition of large doses of morphia or opium without interfering with their anodyne and hypnotic effects. Whether it has been employed in the treatment of chloral poisoning, or whether it has been given along with chloral, as it has with opium where cardiac or pulmonary complications are present I am not aware, but, to judge from the success which attended its employment in the above instance, I think its administration in such cases worthy of a trial. Aberdeen.
EXIHUMATION $\Lambda$ ND EXAMINATION OF A BODY WHICH HAD BEEN BURIED TEN MONTHS.

By FREDERICK WALTER LOWNDES, M.R.C.S. ENG., SURGLON TO THE LIVERPOOL POLICE.

ON November 16th, 1883, I attended at Ford Cemetery, near Liverpool, at the request of the police authorities, to witness the exhumation and to examine the body of Mar. garet Jennings, who had died ten months previously under circumstances suggestive of her having been poisoned by some irritant, most probably arsenic. The cemetery is situated four miles from Liverpool, and is for the exclusive use of Roman Catholics. On my arrival shortly before 9 A.M. I was conducted to the public portion, which stands higher than the other part of the cemetery, is formed of sand mixed with clay, and appeared dry and well suited for its purpose. I was shown a grave which had been just opened, and from which two bodies had been already re. moved. A colfin was lying at the bottom, from which a plate had been removed; it bore the inscription "Margaret Jennings, died 25th January, 1883, aged 18 years." The colfin was a pine one and perfectly intact; it and the coffin plate were identified by the man who made them and conducted the funeral. The death had taken place within the jurisdiction of the coroner of Liverpool ( $\mathrm{Mr}$. Clarke Aspinall), and as the cemetery was in the district of the county coroner, the late Mr. Barker, it was arranged by both gentlemen that permission should be obtained from the Home Secretary to remove the body to Liverpool. The coffin was accordingly removed to the Prince's Dock dead-house, and opened there in my presence. The grave clothes were entire but much soiled by decomposition, and there was some effluvium at first. The face was much discoloured, the hair loosening from the scalp, the eyes and part of the nose had been destroved, the teeth were loosening, the outer skin was peeling off, but the nails on the fingers and toes were firmly adherent. The body was identified in my presence as that of Margaret Jennings br her father and a female friend. On removing the clothes found the surface much discoloured, the outer skin came away with the clothes, the thoracic and abdominal parietes remained intact. The body was that of a female above the age of puberty, of rather short stature but well developed. There was a considerable quantity of fat in the walls of the chest and abdomen. In the chest I found the lungs much decomposed, they were quite collapsed and broken down the heart was softened, and it was impossible to form any idea of the condition of it or the lungs at the time of death. In the abdomen the stomach and duodenum were somewhat softened and were empty. There was a greasy appearance all over the viscera, which reminded me rather of the dissecting room, and which I have seen described somewhere as characteristic of arsenical poisoning, though I cannot give the reference. There was also a yellowish tinge about some of the large intestines. I remored the whole of the abdominal and pelvic viscera into five glass. stoppered, wide-mouthed bottles, as follows:- -1 . Stomach and duodenum. 2. A large portion of the liver (threefourths), spleen, and left kidney. 3. The large intestines except the rectum. 4. The small intestines except the duodenum. 5. The rectum, bladder, and uterus, The bottles were all covered with skin leather, well secured and sealed with two private seals. I opened the head and found the brain in a liquid state; the spinal cord at its upper part was well preserved. On examining the viscera more minutely with Mr. Edward Davies at the Royal Institution Laboratory, some days after, I found the stomach and duo denum of a dark-red colour internally, the small and largo intestines presented reddened patches at different parts excepting a small portion of fæcal matter in the large in testine, they and the rest of the intestinal canal were emptr. Mr. Davies found arsenic in the stomach and duodenum liver, and kidney. Subsequently, in conjunction with Dr. Campbell Brown, he found arsenic in the spleen and in the small intestines, and it was estimated by them that the whole quantity present in the viscera was equivalent to a quarter of a grain.

The deceased was attended shortly before her death by $\mathrm{Mr}$. Rafter, who found her suffering from an attack of pnet monia. He was surprised at the death, which was unex- 
pected by him; he certified it as due to pneumonia. It was carefully concealed from him that the deceased suffered from vomiting, purging, and intense pain in the abdominal region. Mr. Rafter expressed his opinion, after hearing all the evidence, that the deceased had died from poisoning by arsenic.

Liverpool.

\section{CONSERVATISM OF STRENGTH IN HIP, KNEE, AND SPINAL DISEASE.}

BY J. SHERWOOD STOCKER, M.D. LOND., SENIOR PHYSICIAN, WESTERN GENERAL DISPENSARY, \&C.

I HAVE had lately to consider how the strength may be maintained in delicate children when such children have been and are weakened from spinal and articular disease of the knee-joint, such cases frequently requiring a poroplastic jacket, with the application of a Thomas's splint on the diseased limb, with a metal patten on the boot of the sound limb, in order that the patient may be enabled to walk. In these cases the usual plan is to place the iron patten on the boot, without any special non-conducting thermal medium between the sole of the boot and the foot of the child. From this circumstance a large amount of free heat is abstracted from the child, at the expense of its nutrition, thus weakening the child; and even on the diseased limb the nearness of the iron, unprotected by any covering, withdraws the free heat by radiation. To obviate the loss of heat to the sound limb I would have two thicknesses or layers of flannel (placed crossways), with silk and cork inserted between the sole of the boot and the iron; or, perhaps, some thin felt might be as good or better. To save the loss of heat to the diseased limb. I would advise that the iron be protected by a covering of leather or flannel.

Montagu.square, $\mathbf{W}$.

\section{A ittirtor}

of

\section{HOSPITAL PRACTIC, BRITISH AND FOREIGN.}

Nullaautem estalia pro certo noscendivia, nisi quamplurimas et morborum et dissectionum historias, tum aliorum tum proprias collectas habere, et Inter se comparare.-Morgı gar De Sed, et Oaus, MKorb., lib. ir. Procminm.

\section{ST. THOMAS'S HOSPITAL.}

MULBERRY CALCULUS REMOVED BY LITHOTOMY ; CURE, (Under the care of Mr. SydNey JoNes.)

For the notes of the following case we are indebted to Mr. W. H. Battle, surgical registrar.

H. B- - a fishmonger, aged twenty-two, of sanguine temperament, was admitted on October $9 t h$, and left cured December 5th, 1883. His father suffered from gout, but the other members of the family were healthy. He himself, a stout well-built man, had had no previous illness, excepting measles when young; but for the last seven years he had suffered from pain coming on at intervals of a sharp burning character, in the lower part of the abdomen and in the perineum; the pain, when most severe, extended along the urethra, and was very marked in the glans penis. The pain was increased by jolting in a cart and also by walking, but would be temporarily relieved in the latter case by a jerk of the leg or a twist of the body; his urine on such occasions was dark-red, and very thick. The pain was usually severe at the end of micturition; occasionally a sudden stoppage in the flow would take place. About a fortnight before admission micturition became very frequent at night, and about a week before this frequent micturition troubled him both day and night. He then applied at the out-patient department, when a stone was struck. When admitted the above symptoms continued, and on sounding a hard stone with a roughened surface was readily found, the measurement when taken by the lithotrite being found to be $1 \frac{1}{8}$ th of an inch. The prostate gland was found to be somewhat enlarged, but not tender. Urine, sp. gr. 1023, pale, somewhat bloody, with a slight trace of albumen, some mucus, amorphous urates, crystals of phosphates, some epithelial and pus cells.

Oct. $17 \mathrm{th}$. - The frequency of micturition is less marked since the patient has been kept in bed, and there has been less pain. Yesterday the urine was decidedly alkaline, the quantity of albumen slightly increased, but there have been no casts discovered. At 1.30 P.M. Mr. Sydney Jones performed the operation of lateral lithotomy, quickly extracting a large, irregular mulberry calculus; the vessels accessible to ligature were secured by catgut, and forceps were left on the deeper vein. The umbrella tube was then inserted and plugged with lint soaked in carbolised oil. The calculus was of the mulberry form, coated with phosphates and weighed 300 grs. At 5.30 P.M. there had been a good deal of hæmorrhage, and the wound was re-ulugged. The pulse was rather feeble, and the patient suffering a good deal from shock.-18th: It was necessary to re-plug the wound soon after midnight, there having been considerable oozing. At $4.30 \mathrm{~A} . \mathbf{M}$. Mr. Sydney Jones was sent for, the oozing not having ceased. He removed the plugs and forceps excepting two which secured deep and rather large vessels, exposed the wound to the air, and had ice-bags placed in the groins. After this the oozing was comparatively slight; but at 11 o'clock the patient was very blanched and bis pulse 134 , very small. The temperature became normal, having been below normal since the operation, but rose to $102^{\circ}$ at night. - 19th : The patient slept well ; had passed a large quantity of urine by the wound; his pulse was much stronger but still fast, 124 . At 3 P.M. the forceps were removed, and there was no hamorrhage.

From this date he progressed rapidly. On Nov, 2nd the urine came from the urethra as well as from the wound, on the 11th only from the urethra, but on the 19th it again came partly through the wound. He soon, however, passed it entirely by the urethra, and had no further trouble. The rapidity of the pulse diminished, and it increased in volume and strength, being only 88 on the 22 nd. The temperature, which had become normal, rose to $100.8^{\circ}$ in the evening of Nov, 1 st, $104^{\circ}$ on the 2 nd, gradually fell through the $3 \mathrm{rd}$, was not higher than $994^{\circ}$ on the $4 \mathrm{th}$, but reacbed $1014^{\circ}$ on the 5th. A corresponding rise took place on the 13th, 14th, $15 \mathrm{th}$, and $16 \mathrm{th}$, when it rose to $103 \cdot 6^{\circ}$, and the patient had some shivering and vomiting. On neither occasion could the reason for this be ascertained.

RETENTION OF URINE DUE TO THE PRESENCE OF OXALATE OF LIME CALCULUS IN URETHRA; PERINEAL SECTION; SECOND CALCULUS IN BLADDER; REMOVAL BY LATERAL LITHOTOMY

(Under the care of Mr. Sydney JoNEs.)

For the notes of the following case we are indebted to W. H. Battle, surgical registrar.

J. N-, aged eleven, at school, was admitted into the Albert Ward on Oct. 10tb, and left cured Nov. 25th, 1883.

On the day of admission the boy came to the hospital complaining of inability to pass his urine, and this was stated to have come on for the first time three days before and to have persisted during the whole time. There had previously been no symptoms pointing to the presence of stone. The bladder had been aspirated above the pubes before coming to hospital. On passing a catheter a stone could be detected in the urethra corresponding to a swelling situated in the perineum just behind the scrotum. It could not be pushed forward, but seemed to move towards the bladder, when an attempt was made to press it in that direction. The bladder was very much distended; and the patient was in considerable pain.

Soon after admission Mr. Sydney Jones operated, ether baving been administered and the patient placed in the lithotomy position. The stone was grasped between the left thumb and forefinger, and an incision about an inch long made in the median line down to the stone, which was pressed out from the wound as the incision freed it. The hromorrhage was slight, and easily arrested; about fifteen ounces of urine were drawn off, the catheter tied in the bladder, and carbolised oil lint placed over the wound. The stone was about five-eighths of aninch in length, thicker at one end, blackish in culour and nodulated, eviaently oxalate of lime ; it weighed sixteen grains. There was no abnormal rise of temperature after this operation until the 18th, when at 4 A.M. he complained of intense pain over the region of the bladder, and by means of the catheter, which was tied in, another stone was felt, and the pain complained of was relieved by moving this. On this day the temperature rose to 